Article

\title{
Combining Hydrologic Analysis and Life Cycle Assessment Approaches to Evaluate Sustainability of Water Infrastructure: Uncertainty Analysis
}

\author{
Hassan Tavakol-Davani ${ }^{1}{ }^{1} *$ (D) , Reyhaneh Rahimi ${ }^{1}$, Steven J. Burian ${ }^{2}$, Christine A. Pomeroy ${ }^{2}$, \\ Brian J. McPherson ${ }^{2}$ and Defne Apul ${ }^{3}$ (D) \\ 1 Department of Civil, Construction and Environmental Engineering, San Diego State University, \\ 5500 Campanile Dr., San Diego, CA 92182, USA; rrahiminahouji2237@sdsu.edu \\ 2 Department of Civil and Environmental Engineering, University of Utah, 110 Central Campus Drive, \\ Salt Lake City, UT 84112, USA; steve.burian@utah.edu (S.J.B.); christine.pomeroy@utah.edu (C.A.P.); \\ b.j.mcpherson@utah.edu (B.J.M.) \\ 3 Department of Civil and Environmental Engineering, University of Toledo, 2801 W. Bancroft St., MS 307, \\ Toledo, OH 43606, USA; defne.apul@utoledo.edu \\ * Correspondence: htavakol@sdsu.edu
}

Received: 30 September 2019; Accepted: 2 December 2019; Published: 9 December 2019

check for updates

\begin{abstract}
The goal of this research is identifying major sources of uncertainty of an environmentally-sustainable urban drainage infrastructure design, based on hydrologic analysis and life cycle assessment (LCA). The uncertainty analysis intends to characterize and compare relative roles of unreliability, incompleteness, technological difference, and spatial and temporal variation in life cycle impact assessment (LCIA) data, as well as natural variability in hydrologic data. Uncertainties are analyzed using a robust Monte Carlo simulation approach, performed by High Throughput Computing (HTC) and interpreted by Morse-Scale regression models. The uncertainty analysis platform is applied to a watershed-scale LCA of rainwater harvesting systems (RWH) to control combined sewer overflows (CSOs). To consider the watershed-scale implications, RWH is simulated to serve for both the water supply and CSO control in an urban watershed in Toledo, Ohio, USA. Results suggest that, among the studied parameters, rainfall depth (as a hydrologic parameter) caused more than $86 \%$ of the uncertainty, while only $7 \%$ of the uncertainty was caused by LCIA parameters. Such an emphasis on the necessity of robust hydrologic data and associated analyses increase the reliability of LCA-based urban water infrastructure design. In addition, results suggest that such a topology-inspired model is capable of rendering an optimal RWH system capacity as a function of annual rainfall depth. Specifically, if the system could capture 1/40th of annual rainfall depth in each event from rooftops, the RWH system would be optimal and, thus, lead to minimized life cycle impacts in terms of global warming potential (GWP) and aquatic eco-toxicity (ETW). This capture depth would be around $2.1 \mathrm{~cm}$ for Toledo (given an $85 \mathrm{~cm} /$ year rainfall and $200 \mathrm{~m}^{2}$ typical roof area), which could be achieved through an RWH system with $4.25 \mathrm{~m}^{3}$ capacity per household, assuming a uniform plan for the entire studied watershed. Capacities smaller than this suggested optimal value would likely result in loss of RWH potable water treatment savings and CSO control benefits, while capacities larger than the optimal would likely incur an excessive wastewater treatment burden and construction phase impacts of RWH systems.
\end{abstract}

Keywords: combined sewer overflow; high throughput computing; life cycle assessment; rainwater harvesting; topology-inspired regression; uncertainty analysis 


\section{Introduction}

Designing and retrofitting urban drainage infrastructure to meet water quality standards is a challenge for more than 700 combined sewer communities in the U.S. [1]. These communities discharge diluted sewage directly into adjacent water bodies when the drainage system is overwhelmed [1]. These point sources of discharge are referred to as combined sewer overflows (CSOs). There are two types of urban drainage infrastructures that are centralized and distributed. The centralized system collects sewage from all households of an area, and transport them at long distances to one or several central treatment plants. In this system, stormwater can be collected in either combined sewers or in a separate stormwater drain. While, in distributed systems, the treatment and disposal or reuse of the effluent are close to the source of generation. Traditional drainage infrastructure design relies on hydrologic considerations [2-4], which typically lead to centralized, energy-intensive infrastructure solutions. Recently, however, the application of life cycle assessments that contributes to environmentally-sensitive designs is gaining popularity [5-9]. The life cycle assessment determines the cradle-to-grave environmental impacts of products, processes or services, through production, usage, and disposal associated with the life cycle of a product or infrastructure [10]. Hence, incorporating the Life Cycle Assessment (LCA) into the design, analysis, and planning helps identify and quantify the relative environmental benefits of distributed infrastructure compared to centralized solutions for urban drainage [11], including CSO control [12-14].

Hydrologic analysis in traditional urban drainage design focuses on the operation phase. Therefore, it may represent watershed-scale outcomes of different climatic, anthropogenic, and other scenario conditions [15-17] LCA can provide a complement to hydrologic analysis to enable more holistic decision-making by modeling all life cycle phases of the infrastructure (e.g., manufacturing of the materials and operation of the infrastructure) and by considering a broader set of sustainability criteria. However, most studies are limited to building-scale infrastructure without including hydrologic assessment at the watershed scale [6,8,18-22]. Given the recent movement toward the watershed-scale LCA of urban drainage practices [12,23], making a transition to a more cohesive hydrologic-LCA analysis is appropriate. Improving the comprehension of uncertainty and how it may influence system specifications and design can guide this transition.

Life cycle impact assessment (LCIA) data are subject to uncertainties from several sources, depending on the quality of the data [24]. These sources of uncertainty are highlighted by Weidema et al. [25]: unreliability, incompleteness, technological difference, spatial variation, and temporal variation. Unreliability refers to data that are partly or completely estimated rather than measured. Incompleteness is the condition that representative data are not obtained from all relevant sites. Technological, spatial, and temporal variations exist in datasets obtained from different technologies, locations, and time periods. Use of hydrologic data amplifies these uncertainties because these data introduce natural variability and, thus, additional uncertainty that cannot be reduced by more measurements. Apart from uncertainties caused by data, an incomplete or biased model structure also propagates uncertainties into outputs [26]. Reported LCA results may be misleading if potential sources of uncertainty are not addressed, especially in the case of comparing design alternatives for decision-making $[27,28]$. Identifying major sources of uncertainties with relative impacts on the final LCA results is indispensable [26,29-31] for effective application of hydrologic analysis and LCA for a sustainable, watershed-scale design of urban drainage systems.

Uncertainty quantification aims find ways to increase the reliability of LCA-based conclusions [32], and it helps support interpretation of LCA results, according to the ISO 14040 [10]. Such statistically-based analysis determines the density of plausible outputs around an expected value based on uncertainty propagated from different sources, instead of inflexible outputs of deterministic (non-statistical) methods. Despite numerous uncertainty studies of LCA applications in different fields, including energy systems [33-35], electronic devices [36], farming [37,38], transportation systems [39], and building materials [40]. The uncertainty analysis of LCA in the water infrastructure evaluation has been studied by only a few researchers recently [24,41,42]. While not suited to all 
studies, Monte Carlo simulation is most commonly recommended for assessment of the parameter uncertainty in LCA $[24,25,27,39,41-45]$. However, two recently published LCA studies on CSO control infrastructure $[12,13]$ only investigated the possible range of LCA results using sensitivity analysis, without identifying the sources and relative effects of the different specific uncertainty components.

Therefore, the present research intends to identify and quantify the sources and effects of uncertainties in a sustainability-based urban drainage infrastructure design. This research augments the body of urban drainage sustainability literature, considering the explained gap in the literature regarding the uncertainty characterization of the urban drainage infrastructure design. Decentralized (or distributed) water infrastructure, specifically rainwater harvesting (RWH), is a primary focus of this paper because of widespread interest of RWH for both drainage and water supply purposes. Given the recent need to consider environmental sustainability in addition to cost and traditional stormwater control criteria, RWH may be found an attractive solution if robust analyses support this [46-52]. The primary objective of this paper is to develop a framework for such analyses.

An integrated hydrologic and LCA modeling framework is presented. Then, using Monte Carlo simulation, a comprehensive uncertainty analysis is conducted to investigate and quantify the major sources of uncertainties and their relative impacts. To perform the uncertainty analysis and interpret the results, two computational techniques are employed: high throughput computing (HTC) and partition-based, topology-inspired maps based on Morse-Smale regression [53,54]. The former provides the computational resource for iterative time-consuming simulations and the latter assists in detecting the main drivers within local regions of the results to identify different system responses.

\section{Methodology}

This section presents (1) the goal and scope of the uncertainty analysis, (2) an integrated hydrologic analysis and LCA framework for the application of the uncertainty analysis, (3) uncertainty analysis procedure to quantify the relative impacts of uncertainty components, and (4) details of the case study application.

\subsection{The Goal and Scope of Uncertainty Analysis}

This sub-section describes the sources of uncertainties in an integrated hydrologic-LCA design, and then delineates the specific sources studied in this research. Both in LCA and in hydrologic literature, the sources of uncertainty can be categorized as data uncertainty, model structural uncertainty, and decision uncertainty $[25,27,30,55-58]$. Of these three sources, data uncertainty often receives higher priority and is the most commonly analyzed one. We focused on data uncertainty since it is the first step toward understanding integrated frameworks similar to one developed in this study. Specifically, we compared the effects of uncertainty associated with hydrologic data versus the effects of uncertainty in LCIA data in an LCA-based urban water infrastructure design. The hydrologic data uncertainty arises from inaccurate measurements and natural variability related to the operation of the water infrastructure. The uncertainty in LCIA arises from unreliability, incompleteness, technological difference, spatial variability, and temporal variability of data, per Weidema et al. [25]. It is worth noting that assessing the LCIA characterization factor uncertainty as discussed by Rosenbaum et al. [59] and Wender et al. [60] is beyond the scope of this study.

\subsection{Integrated Hydrologic Analysis and LCA Framework}

We selected the uWISE (urban Water Infrastructure Sustainability Evaluation) approach of Tavakol-Davani et al. [61], an integrated hydrologic analysis, and LCA framework, for the uncertainty analysis application. The uWISE framework uses a dynamic urban hydrologic model to simulate the effects of the water infrastructure on the hydrology of the watershed in terms of supplied water and stormwater (Figure 1). The model inputs include the characteristics of the water infrastructure components as well as hydrologic inputs, e.g., rainfall and dry weather flow. The hydrologic module computes the hydrologic response of sub watersheds and the hydraulic response of conveyance 
networks, explained in Section 2.2.1. Then, uWISE takes the outputs of the hydrologic model to a process-based LCA model (Section 2.2.2). This LCA model translates the energy consumption and pollution caused by the water supply and treatment processes (water and wastewater) into life cycle environmental impacts. To perform the LCA model calculations, uWISE combines hydrologic model outputs from the operation phase with the materials and energy from the construction and maintenance phases. In sum, uWISE forecasts the life cycle impacts for selected impact categories.

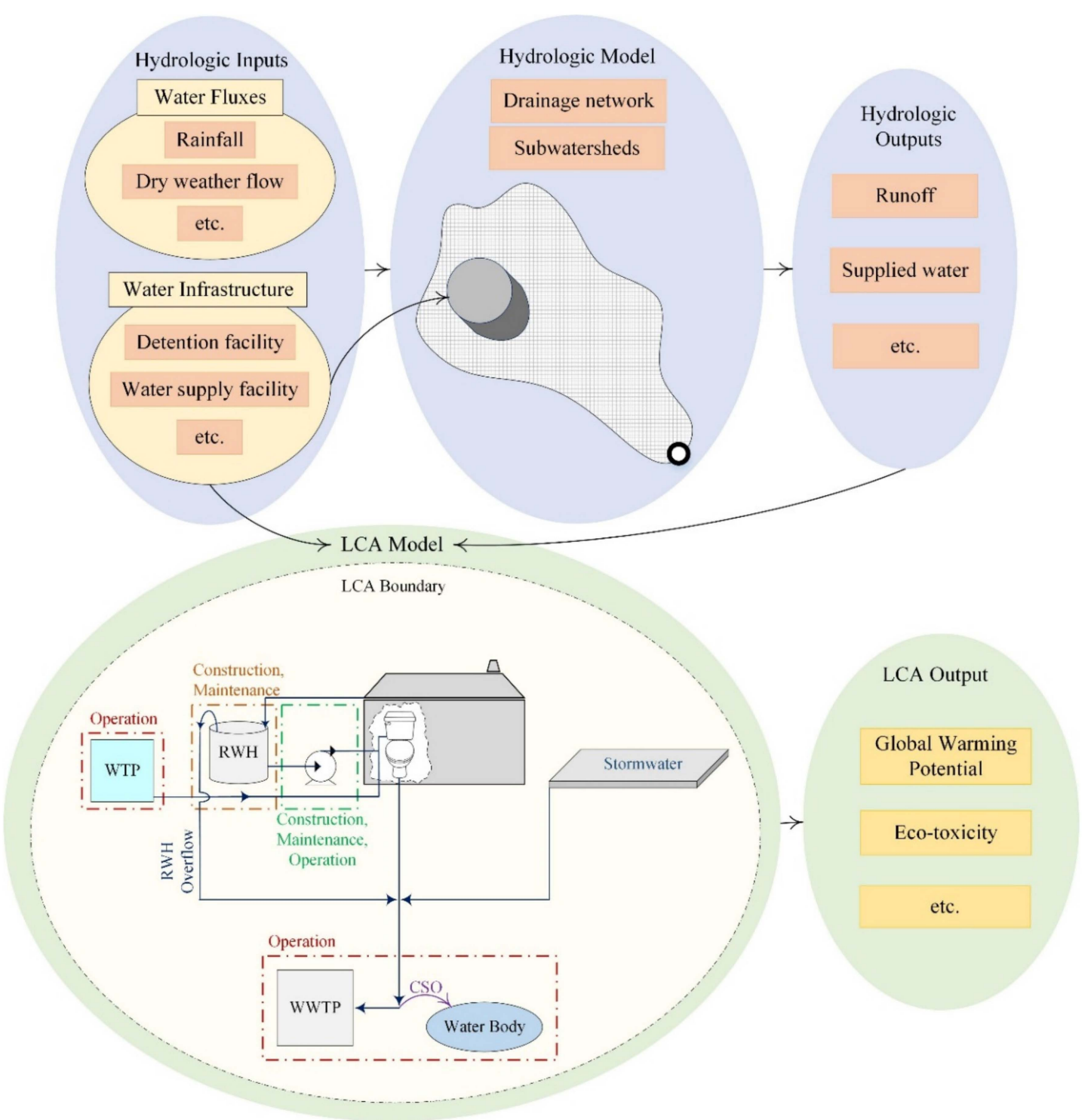

Figure 1. The uWISE framework. The upper row shows the Hydrologic and Hydraulic $(\mathrm{H} \& \mathrm{H})$ model components and the lower row shows the LCA model components. The LCA model inputs consist of materials and energy requirement of the water infrastructure as well as outputs of the hydrologic model. The LCA system boundary indicates that the operation phases of both the Water Treatment Plant (WTP) and the Wastewater Treatment Plant (WWTP) would be affected by a watershed-scale RWH implementation that is included. Construction and maintenance phases of all RWH components are considered. For pumps, the operation phase impacts in terms of electricity consumption are also considered. The system boundary also includes environmental impacts of CSO pollutants to freshwater bodies. 


\subsubsection{Hydrologic Model}

Hydrologic and Hydraulic $(\mathrm{H} \& \mathrm{H})$ model simulate rainfall-runoff flow to predict the extent of creek and river water levels as well as flooding and to test ways to reduce the flooding without actually constructing the project. These models inform decisions about selecting and implementing flood reduction and restoration projects. In this study, the U.S. EPA Storm Water Management Model version 5 (SWMM) [62] was employed as the H\&H model for continuous hourly simulation of the representative year. The SWMM simulates the land surface as delineated sub watersheds, governed by the nonlinear reservoir equation as well as Manning's equation for overland flow. Water transport in conduits is addressed with the Dynamic Wave method, and SWMM solves the one-dimensional Saint Venant flow equation at each time step. The capture of rainfall from rooftops by RWH is simulated using the Rain Barrel Low Impact Development module in SWMM [51,61]. To mimic the release from RWH units, underdrain flows from rain barrels (governed by the orifice equation) are matched to supply indoor demands. Among the numerous hydrologic model outputs, the following were selected for the uWISE framework: CSO volume, CSD (combined sewage delivered to treatment plant) volume, and rainfall use (volume of supplied demand by RWH) volume.

\subsubsection{LCA Model}

Life Cycle Assessment is a standard approach to estimate the consumption of resources and emissions associated with the life cycle of a product, process, or infrastructure [10]. The LCA has four steps: outlining the goal and scope of the analysis (described in Section 2.1), gathering the data needed for all life cycle stages to create a life cycle inventory (LCI), quantifying the impacts via life cycle impact assessment (LCIA) methods, and interpreting the results. In LCA studies of water and wastewater treatment plants, $1 \mathrm{~m}^{3}$ of treated water [63-66] or wastewater $[28,67]$ is often used as the Functional Unit (FU). The drainage area has been used as the functional unit in prior watershed scale LCAs [12,13]. In this study, since the goal of the analyzed infrastructure is to reduce CSOs, the functional unit was defined as $1 \mathrm{~m}^{3}$ reduction of CSO volume over the life cycle of facilities. The selected functional unit sets the system boundaries of the LCA as depicted in a conceptual schematic (Figure 1). This boundary includes the operational phases of the WTP and WWTP because both would be affected by RWH. The SWMM does not include a water distribution module. Therefore, to capture the effects on WTP, supplied demand by RWH was considered as an avoided burden from the WTP. Assuming when the harvested rainfall from RWH systems is used to meet indoor demands, there will be a direct reduction on the target supply volume for WTP. A 75-year analysis period was considered since it is recommended as the average building life cycle and is used in other RWH studies [18]. Replacement of RWH components during this analysis period was considered as listed in Table 1. The LCI and LCIA methods were considered as follows.

Life Cycle Inventory. The data for the environmental impacts of processes in this study were adapted from the Ecoinvent database (Ecoinvent, 2.2) using GaBi 6 [68]. The components of construction and maintenance phases are summarized in Table 1 (additional data are provided in the Supplementary Materials). The operation phase components varied through the uncertainty analysis process. To determine the role of CSOs in degrading the water quality, we utilized the historical concentration records of the following pollutants for LCA modeling: cadmium, chromium, copper, lead, nickel, zinc, mercury, arsenic, manganese, selenium, cyanide, phenols, ammonia, organic nitrogen, nitrate, nitrite, and total phosphorus. These pollutants impact the environment once released to surface water bodies. To inventory these flows, the concentrations of pollutants in CSOs were obtained from the City of Toledo engineering personnel. The available data came from different discharge points along the study area. Therefore, an average value was used for this study.

Life Cycle Impact Assessment. The TRACI (Tool for the Reduction and Assessment of Chemical and other environmental Impact) method was used in this study since it is based on U.S. impact data [69]. Among the TRACI impact categories, we selected the Global Warming Potential (GWP) and aquatic Eco-toxicity (ETW) for this study to focus on the environmental and water quality effects of the 
studied urban water infrastructure. These two impact categories were reported as the ones that would be highly affected by RWH implementation in a combined sewer network, compared to Eutrophication Potential and Ozone Depletion Potential [61].

Table 1. Components and impacts of the RWH system for one building using the TRACI method. Impacts of construction and maintenance phases are provided in this table, and the values of operation phase components are provided by the hydrologic model varying in each Mont Carlo run. A sample value for impact in the operation phase for implementing RWH have a $2.65 \mathrm{~m}^{3}$ cistern to supply toilet flushing demand.

\begin{tabular}{|c|c|c|c|c|c|c|}
\hline Phase & Component & $\begin{array}{c}\text { Input } \\
\text { Quantity }\end{array}$ & $\begin{array}{l}\text { Input } \\
\text { Unit }\end{array}$ & $\begin{array}{c}\text { Energy } \\
\text { (kwh) }\end{array}$ & $\begin{array}{c}\mathrm{GWP} \\
\left(\mathrm{k} \mathrm{CO}_{2} \mathrm{e}\right)\end{array}$ & $\begin{array}{c}\text { ETW } \\
(\text { CTU eco) }\end{array}$ \\
\hline \multirow{5}{*}{ Construction } & Concrete (pad) & 0.23 & $\mathrm{~m}^{3}$ & 190.6 & 60.3 & 64.6 \\
\hline & Cistern (galvanized steel) & 100.5 & $\mathrm{~kg}$ & 799.5 & 272.5 & $-243.4^{(2)}$ \\
\hline & Pump & 13.9 & $\mathrm{~kg}$ & 39.9 & 12.5 & $-14.8^{(2)}$ \\
\hline & PVC pipes & 14.8 & $\mathrm{~kg}$ & 304.1 & 42.0 & 3.0 \\
\hline & Materials transportation $(1)$ & $66,926.1$ & $\mathrm{~kg}-\mathrm{km}$ & 19.7 & 4.9 & 2.9 \\
\hline \multirow{4}{*}{ Operation ${ }^{(3)}$} & Pump energy & 864 & MJ & 864 & 599.6 & 22.4 \\
\hline & Potable water treatment ${ }^{(4)}$ & -3799.21 & $\mathrm{~m}^{3}$ & $-13,221.3$ & -1534.9 & $-11,017.7$ \\
\hline & $\mathrm{CSOs}^{(4)}$ & -2840.18 & $\mathrm{~m}^{3}$ & - & - & $-73,560.8$ \\
\hline & Combined sewage treatment $(4)$ & 3284.22 & $\mathrm{~m}^{3}$ & $10,443.8$ & 1913.9 & $20,567.4$ \\
\hline Maintenance & Cistern and pump replacement & Mixed & - & 1887.2 & 634.5 & $-589.2^{(2)}$ \\
\hline
\end{tabular}

$\ddagger$ Cistern replacement in 30 years and pump replacement in 10 years were assumed [70]. ${ }^{(1)}$ Estimated based on the weight of materials and an assumed $100 \mathrm{~km}$ average distance from the plant to the installation point [71]. (2) ETW is negative for cisterns and pumps based on a GaBi database due to considering the effects of landfilling at the end of their life cycle. ${ }^{(3)}$ The values for the operation phase are the sampled calculation for the RWH with a $2.65 \mathrm{~m}^{3}$ cistern to supply toilet flushing demand. These values differ in each MC run. ${ }^{(4)}$ Values are differences from the existing condition. ${ }^{(5)}$ Aquatic eco-toxicity is expressed in terms of Comparative Toxic Units (CTU eco)

\subsection{Uncertainty Analysis Procedure}

In this section, a comprehensive uncertainty analysis using Monte Carlo simulation is conducted to investigate and quantify the major sources of uncertainties and their relative impacts. To perform the uncertainty analysis and interpret the results, the parameters of interest are selected according to Section 2.3.1 in the first step. Then, two computational techniques are employed including high throughput computing (HTC) (Section 2.3.2) and partition-based, topology-inspired maps based on a Morse-Small regression [53,54] (Section 2.3.3). The former provides the computational resource for iterative time-consuming simulations and the latter assists in detecting the main drivers within local regions of the results to identify different system responses.

\subsubsection{Selected Parameters}

Major sources of uncertainty in the parameters of uWISE are detailed in Table 2. Selected parameters for uncertainty analysis are highlighted in gray (Table 2). Two hydrologic input parameters and two LCIA parameters were selected based on pre-analysis tests, as discussed below. Hydrologic input parameters were selected based on a local sensitivity analysis, i.e., identify the model response to one parameter variation while other parameters are held constant [72]. Parameters whose variation (over the respective possible range) resulted in more than a 30\% change in the annual $\mathrm{CSO}$ volume were picked for the uncertainty analysis, which leads to the selection of rainfall (R) and RWH capacity (C). The importance of $\mathrm{R}$ and $\mathrm{C}$ as significant sources of uncertainty was also confirmed in previous hydrologic studies that focused on rainfall-runoff modeling $[57,73]$ and RWH design [74-78], respectively. 
Table 2. Major uncertainty sources of the uWISE. Selected components for uncertainty analysis in this paper are marked with a gray background.

\begin{tabular}{|c|c|c|c|}
\hline Sub-Model & Component & Uncertainty Type & Data Source \\
\hline \multirow{6}{*}{ Hydrologic } & $\begin{array}{l}\text { Rainfall (R). Illustrated as a part of } \\
\text { water fluxes in Figure } 1\end{array}$ & Input parameter & $\begin{array}{l}\text { Sampled from a normal } \\
\text { distribution for annual rainfall } \\
\text { depth (Figure S1) }\end{array}$ \\
\hline & $\begin{array}{l}\text { Combined network water fluxes } \\
\text { (e.g., Dry Weather Flow, } \\
\text { groundwater flow) }\end{array}$ & Input parameter & Measured data \\
\hline & $\begin{array}{l}\text { Capacity }(\mathrm{C}) \text { of RWH (referred to as } \\
\text { water infrastructure in Figure 1) }\end{array}$ & Input parameter & $\begin{array}{l}\text { Sampled from a gamma } \\
\text { distribution (Figure S1). }\end{array}$ \\
\hline & RWH release rate & Model parameter & $\begin{array}{l}\text { Toilet flushing demand data } \\
\text { for a typical residential } \\
\text { building [51] }\end{array}$ \\
\hline & $\begin{array}{l}\text { Sub watershed characteristics (e.g., } \\
\text { slope, imperviousness, roughness, } \\
\text { infiltration capacity) }\end{array}$ & Model parameters & Measured data \\
\hline & $\begin{array}{l}\text { Conveyance network characteristics } \\
\text { (e.g., details of pipes, regulators, } \\
\text { pumps, outfalls) }\end{array}$ & Model parameters & Measured data \\
\hline \multirow{4}{*}{ LCA } & $\begin{array}{l}\text { Materials and energy requirement } \\
\text { for construction and maintenance } \\
\text { phase of RWH }\end{array}$ & Input parameter & Table 1 \\
\hline & $\begin{array}{l}\text { Materials and energy requirements } \\
\text { for performance phase of RWH }\end{array}$ & Input parameter & Hydrologic model output \\
\hline & $\begin{array}{l}\text { GWP impacts for per unit of CSD } \\
\left(G^{\prime} P_{C S D}\right) \text {-referred to LCA output } \\
\text { in Figure } 1\end{array}$ & Model parameter & $\begin{array}{l}\text { Sampled from a lognormal } \\
\text { distribution (Figure S1) }\end{array}$ \\
\hline & $\begin{array}{c}\text { ETW impacts for per unit CSO } \\
\begin{array}{c}\left(\text { ETW }_{\mathrm{CSO}}\right) \text { - referred to LCA output } \\
\text { in Figure } 1\end{array}\end{array}$ & Model parameter & $\begin{array}{l}\text { Sampled from a lognormal } \\
\text { distribution (Figure S1) }\end{array}$ \\
\hline
\end{tabular}

LCIA parameters were selected based on an LCA study of RWH scenarios at a watershed scale by Tavakol-Davani et al. [61]. In that study, global warming potential (GWP) and eco-toxicity water (ETW) were reported as the impact categories that would be highly affected by RWH implementation in a combined sewer network when compared to Eutrophication Potential and Ozone Depletion Potential. Furthermore, the main drivers for increasing GWP and decreasing ETW were, respectively, found to be CSD and CSO in which each were responsible for more than $40 \%$ of added/avoided impacts [61]. Thus, in this study, GWP per unit of CSD was selected as one of the LCIA model parameters for uncertainty

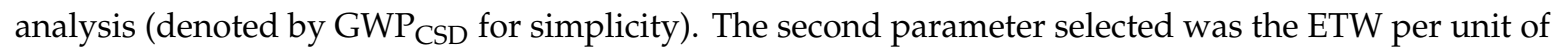
$\mathrm{CSO}$ ( $\left.\mathrm{ETW}_{\mathrm{CSO}}\right)$. Information on probability distribution for the four selected parameters is presented in Supplementary Materials (Figure S1).

\subsubsection{Uncertainty Analysis Technique}

Following recommendations in the literature [24,27,39,41-45,79], a Monte Carlo method (MC) was employed in this study for comparing the effects of input parameter uncertainty (hydrologic data) versus model parameter uncertainty (LCIA data). Since the initiation of MC (e.g., Metropolis and Ulam [80]), it has been globally utilized to obtain a statistical description of the system performance uncertainty [58]. An interesting aspect of the MC application for this study is its non-dependency on calculus-based characteristics in contrast to analytical methods, such as the first-order second-moment (FOSM) method (e.g., Elishakoff et al. [81]). The MC simply evaluates the uWISE function with different sets of parameters in an iterative manner. This is of importance for the present study due to the mathematical complexities of the uWISE, specifically in the hydrologic module. This module consists of several implicit, non-linear functions (e.g., the Saint Venant flow equation) for transporting rainfall through conveyance network elements. 
Some extensions to the MC have been proposed specifically to enhance its mathematical efficiency, such as Markov Chain Monte Carlo (MCMC) with the Metropolis-Hastings algorithm [82,83]. Although these algorithms are widely used in hydrologic modeling to facilitate the analysis of complex spaces (e.g., Vrugt et al. [84], and Zahmatkesh et al. [71]), some researchers disagree about convergence requirements $[85,86]$. The present study followed a fundamental MC instead for simplicity and to avoid these requirements because a High Throughput Computing (HTC) resource was able to provide the sufficient iterations for simulations. A freely-available HTC resource, namely HTCondor [87], was chosen in lieu of other available distributed computing resources, such as High-Performance Computing (HPC) and Graphics Processing Unit (GPU). Similar to Tavakol-Davani et al. [88,89], our selection was due to significantly lower setup costs, a platform-independent structure (cloud-based computing), and the high unit processing speed of HTCondor.

The steps of the MC simulation for this study are diagrammed in Figure 2. Specifically, random sampling of individual parameter space from prior probability distributions is employed to extract a set of parameter values. Then, the parameters are utilized to run the uWISE framework on an HTCondor v.7.8.8 cluster. Next, the changes in outputs are tracked and compared with a convergence threshold, which is explained in the Supplementary Materials. When the convergence criterion is satisfied, probability density of outputs is presented.

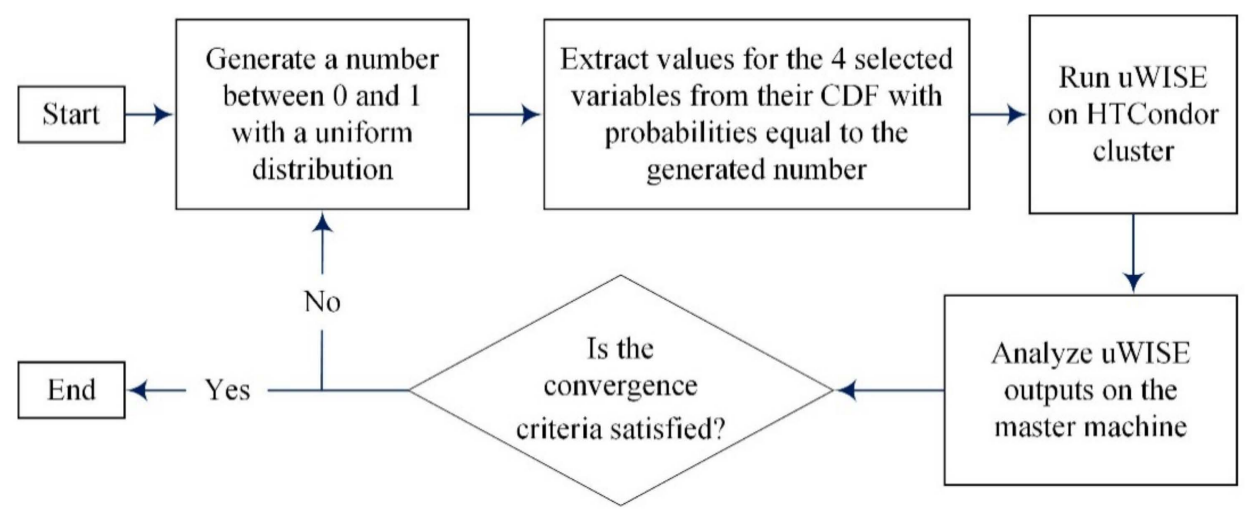

Figure 2. The steps of Monte Carlo simulation to analyze the uncertainties in the results of the uWISE framework using HTCondor.

\subsubsection{Interpreting the Results}

After performing the MC simulation, the portion of uncertainty propagated by each parameter was calculated using the First-Order Sensitivity Analysis method for the MC results [58].

$$
\operatorname{Var}(O)=\sum_{i=1}^{n}\left(\frac{\delta F}{\delta X_{i}}\right)^{2} \times \operatorname{Var}\left(X_{i}\right)
$$

where $F$ is the uWISE model, $X$ denotes the parameters, $O$ represents the model output, and $n$ is the number of considered parameters ( 4 in this study). This equation is applicable only when all the parameters are independent of each other. In such a case, the term $\left(\frac{\delta F}{\delta X_{i}}\right)^{2} \times \operatorname{Var}\left(X_{i}\right)$ presents the portion of uncertainty propagated by variable $X$. The method to verify the independency of parameters with details on calculating the components of Equation (1) are explained in the Supplementary Materials (Figure S1).

Furthermore, a partition-based, topology-inspired model based on the Morse-Smale regression (MSR) technique [53] was adopted to assist in visual interpretation of the MC results. The MSR performs a domain partitioning induced by an approximated version of the topological structure known as the Morse-Smale complex (MSC). The MSC decomposes a space based on gradient flow. Each partition in the MSC represents data whose integral line begins at a specific local minimum 
and terminates at a specific local maximum. This minimum-maximum pair uniquely identifies the partitions of the MSC. Thus, the MSC can be approximated on the MC results by imposing a graph structure and approximating gradient flow as occurring on the edges of the graph. An important property of the decomposed results is that, within each partition, the data is assumed to be monotonic. As such, a linear model can be satisfactorily fitted within each partition. Additional information about this method and its application for the present research are presented in Supplementary Materials (Figure S2).

\subsection{Details of the Case Study Application}

A combined sewer watershed in the City of Toledo, Ohio was used to conduct the uncertainty analysis. The annual average precipitation in Toledo is $85 \mathrm{~cm}$ [90]. The year 1998 is identified as the representative year for Toledo's rainfall. This identification is based on the analysis of rainfall depth and intensity for 1972 to 2001 records by the City of Toledo [91]. The studied watershed known as Eastside consists of $41 \mathrm{sub}$ watersheds with a total area of $9.54 \mathrm{~km}^{2}$. A location map of the tributary sub watersheds, major pipes, and the interceptor of the study area is provided in Supplementary Materials (Figure S3). Tavakol-Davani [92] explained comprehensive details of the watershed. There are 9892 buildings, predominantly residential, in this watershed [93]. Financial and engineering aspects of RWH plans in this watershed are summarized by Tavakol-Davani et al. [51]. In that study, RWH was reported as a cost-effective solution to supply toilet flushing demand and control CSOs ( $48 \%$ cheaper than centralized solutions). Therefore, the present study considered toilet flushing as the end use of interest (Table 2).

The Eastside generates, on average, $1.3 \mathrm{MCM}$ of CSOs annually, which is approximately $60 \%$ of the total annual CSO volume in Toledo. An interceptor in the Eastside watershed with the capacity of $0.25 \mathrm{MCM}$ /day collects combined sewage and delivers it to the Bay View wastewater treatment plant (WWTP). On average, the interceptor conveys $0.16 \mathrm{MCM} /$ day of combined sewage [94].

\section{Results}

\subsection{Hydrologic Analysis Results}

Figure 3 presents the scatter plots of MC simulation for the hydrologic outputs based on 10,000 iterations, which was sufficient to satisfy the convergence criteria. Figure 3a reveals the nonlinear response of rainfall use to a change in RWH system capacity (C). This finding challenges the efficacy of linear approximation of decentralized infrastructure performance for different capacities, e.g., methods that are based on the linear summation of capture depth. In fact, an increase in C will not cause a proportional increase in rainfall use because, as $C$ increases, the chance of a system becoming partially filled (by non-extreme rainfall events) also increases. Eventually, rainfall use will converge to a horizontal asymptote when $C$ reaches the maximum possible capture of rooftop rainwater for each value of annual rainfall (R).

Figure $3 \mathrm{a}$ also illustrates that increasing values of $C$ increase the range of possible rainfall use values. Therefore, for larger systems, variability in $\mathrm{R}$ brings a higher uncertainty for rainfall use. This is because small systems would likely react similarly with various rainfall events (become completely full regardless of the rainwater level), while large systems would be filled to different levels in various rainfall events.

Figure $3 \mathrm{~b}$ shows that $\mathrm{C}$ has a comparatively small effect on $\mathrm{CSO}$, despite a slight nonlinear response of CSO to a change in $\mathrm{C}$ is observed (specifically for high values of $\mathrm{R}$, illustrated with light green to red). This result is attributed to the limited capability of RWH to control CSOs given the existence of other CSO-causing components, e.g., dry weather flow, groundwater flow, rainfall derived infiltration inflows, and the runoff from other impervious areas in sub watersheds. For low values of $R$, relative contribution of rainfall in generating CSOs is low. Therefore, $\mathrm{RWH}$ is ineffective at controlling CSOs (although it may be useful for reducing stormwater pollution loading to waterways caused by 
frequent rainfall events). This finding also provides insight regarding higher efficiency of decentralized drainage facilities when implemented as hybrid systems based on a combination of different types. The horizontal asymptotes represent the maximum capability of RWH to control CSOs for a specific R.
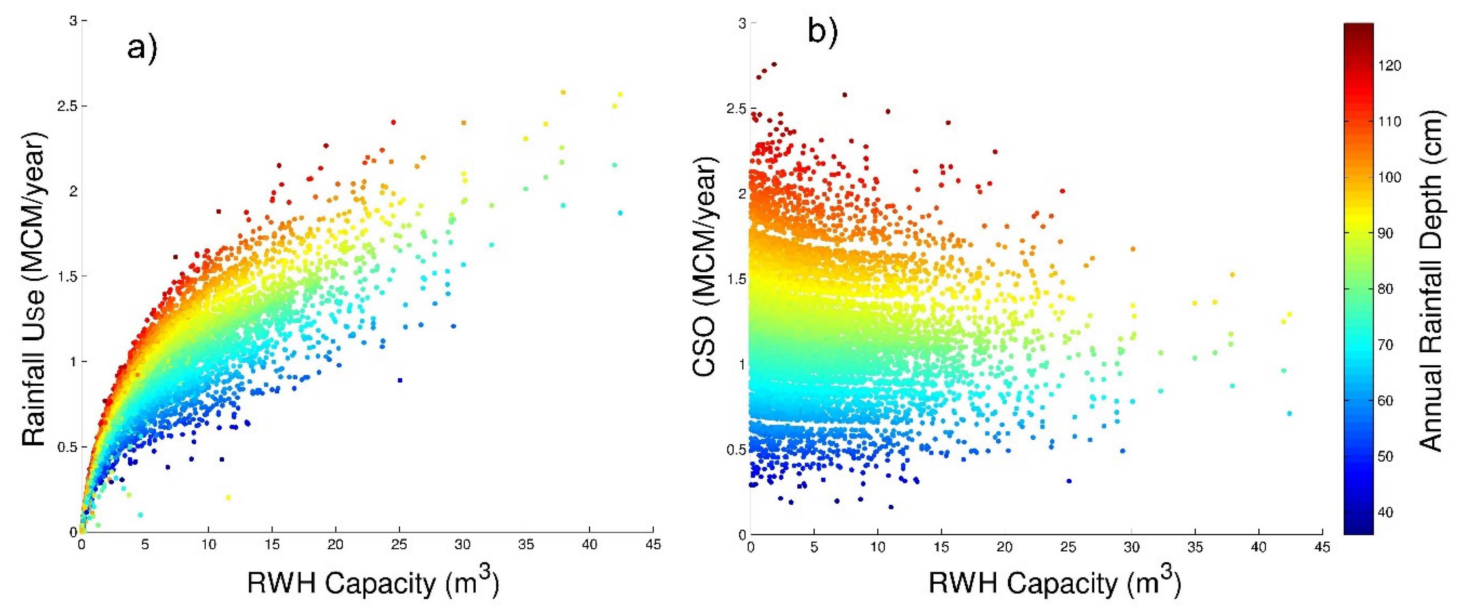

Figure 3. Scatter plots of the MC simulation results for (a) rainfall use; and (b) CSO. Different values for annual rainfall depth are depicted with a blue to red color range. Since CSD has a similar behavior to CSO (but just with an inverse trend), it is not shown as a separate subfigure.

Figure 4 exhibits the probability density of the MC simulation for the hydrologic outputs. According to this figure, the highest probability (mode) of rainfall use and CSO are associated with 0.7-0.8 and 1.1-1.2 MCM/year, respectively. According to Figure 4 and the CSO volume of 1.3 MCM/year without RWH implementation (as presented in Methodology section), a low CSO reduction from the RWH system is expected. On the other hand, noticeable rainfall use is expected for supplying indoor demands (compared to a null rainfall use without RWH implementation). Figure 4 also indicates a higher variance (as a measure for uncertainty) in rainfall use than CSO (variance is $0.16 \mathrm{MCM} / \mathrm{year}$ for rainfall use and $0.12 \mathrm{MCM} /$ year for CSO). This higher variance in rainfall use reflects the entire variance in $\mathrm{R}$ and $\mathrm{C}$, while these two parameters have limited effects on CSO due to the existence of other factors, such as dry weather flow, groundwater flow, and rainfall derived infiltration inflows.

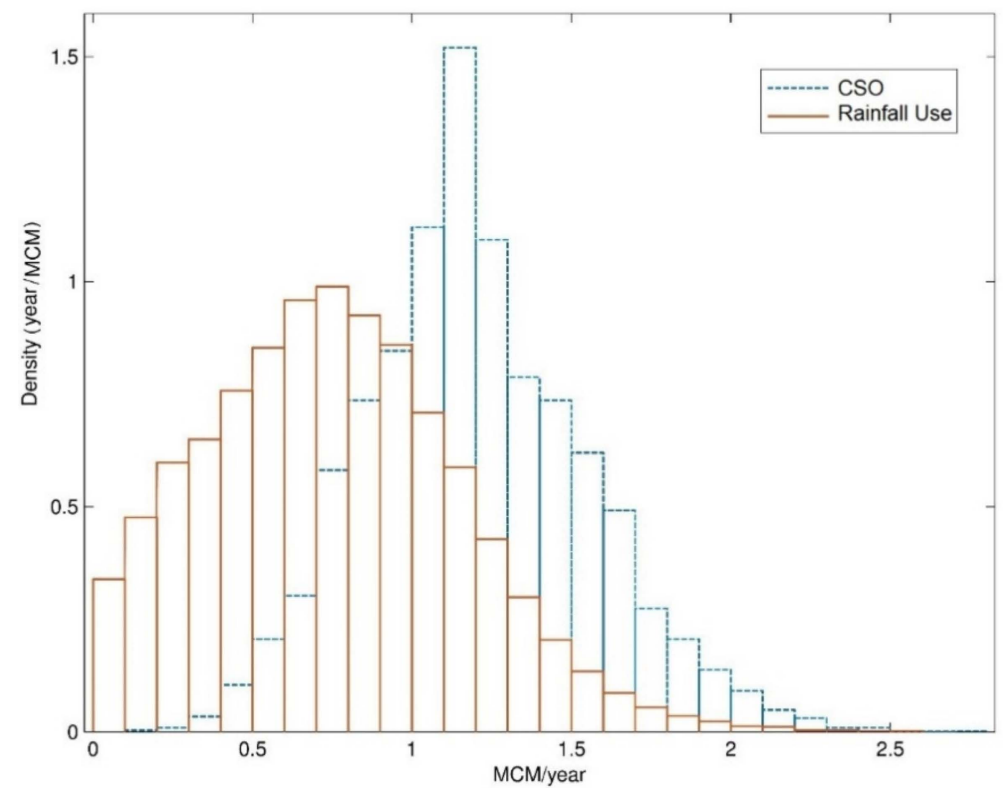

Figure 4. Probability density of the 10,000 MC simulation results for rainfall use and CSO. 


\section{2. uWISE Analysis Results}

The topology-inspired model detected two partitions for the GWP response based on 10,000 outputs, which was sufficient to satisfy the convergence criteria. Figure 5 was assembled to explore the implication of GWP results concerning the two partitions. Analysis of these results suggested that the left partition in Figure 5a is driven by the water supply benefits of RWH, which contributes to the avoidance (reduction) of the potable water treatment burden in WTP, and, thus, has a descending trend. The right partition in Figure $5 \mathrm{a}$ is driven by increased wastewater treatment burden in WWTP as a result of detention effects of RWH, which exhibits an ascending trend. The detention effect of RWH leads to collecting stormwater and transmitting it to WWTP (instead of discharging it as a CSO to water bodies). Therefore, it increases the wastewater treatment burden.
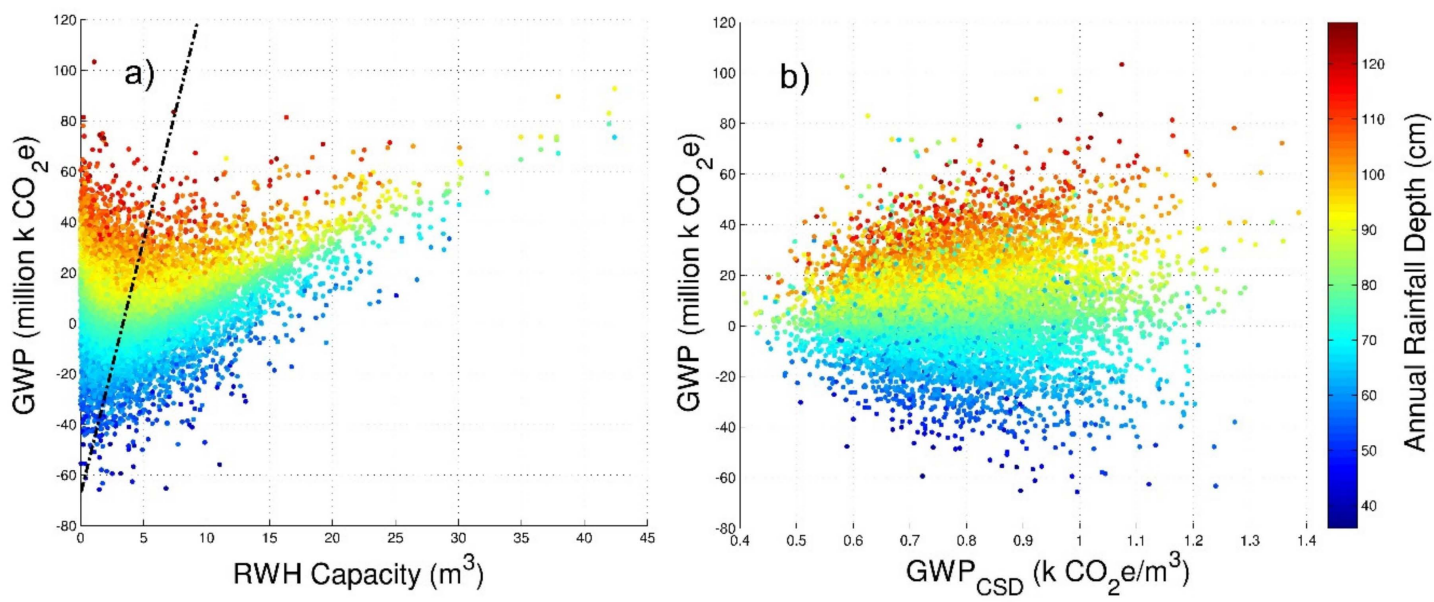

Figure 5. Scatter plots of the MC simulation results for GWP impact corresponding to (a) RWH capacity;

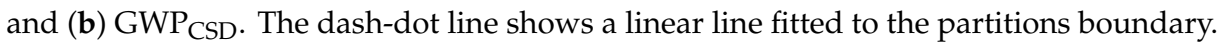

A linear line was fitted to the points located at the boundary of partitions (shown by a dash-dot line in Figure 5a). This line represents an equilibrium between the added and avoided GWP impacts by RWH. This line connects the local minima for different rainfall depths, and, thus, may be interpreted as the optimal system design as a function of $\mathrm{R}$. An interesting point about this line concerns its suggested linear relationship between $C$ and $R$. The optimal system capacity proportionally increases with the increase in annual rainfall depth. When the dash-dot line was analyzed in a two-dimensional space made by $\mathrm{C}$ and $\mathrm{R}$, it was found that $\mathrm{C}$ (in $\mathrm{m}^{3}$ ) approximately equals five times $\mathrm{R}$ (in meters). In other words, the optimal RWH system capacity (in $\mathrm{m}^{3}$ ) for each rainfall annual depth could be calculated by multiplying the annual rainfall depth (in $\mathrm{m}$ ) by 5 (according to the dash-dot line in Figure 5a) per household. This capacity is sufficient to capture 1/40th of annual depth in each rainfall event assuming a typical rooftop of $200 \mathrm{~m}^{2}$ area (e.g., $2 \mathrm{~cm}$ capture in each rainfall event for a year with $80 \mathrm{~cm}$ total depth). Figure $5 \mathrm{~b}$ suggests that high impacts per volume of CSD amplifies the final LCA outputs. However, this effect appears to be trivial when compared to the observed correlation between GWP and R.

Performance of ETW is presented in Figure 6. Figure 6a indicates a slight nonlinear response of ETW to changes in C for high values of $\mathrm{R}$ (illustrated in light green to red) based on 10,000 iterations, which was sufficient to satisfy the convergence criteria. For other values of $R$, no significant response was observed. These correspond to the observations plotted in Figure 3b, which suggests that ETW is primarily driven by CSO. The minimal GWP line is also demonstrated in Figure 6a. This line presents no noticeable reduction in ETW for capacities larger than the dash-dot line plotted (Figure 6a). This observation affirms the optimal behavior of the dash-dot line in terms of ETW in addition to

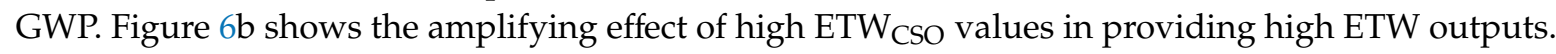
However, this effect was insignificant compared to the observed correlation between ETW and R. 

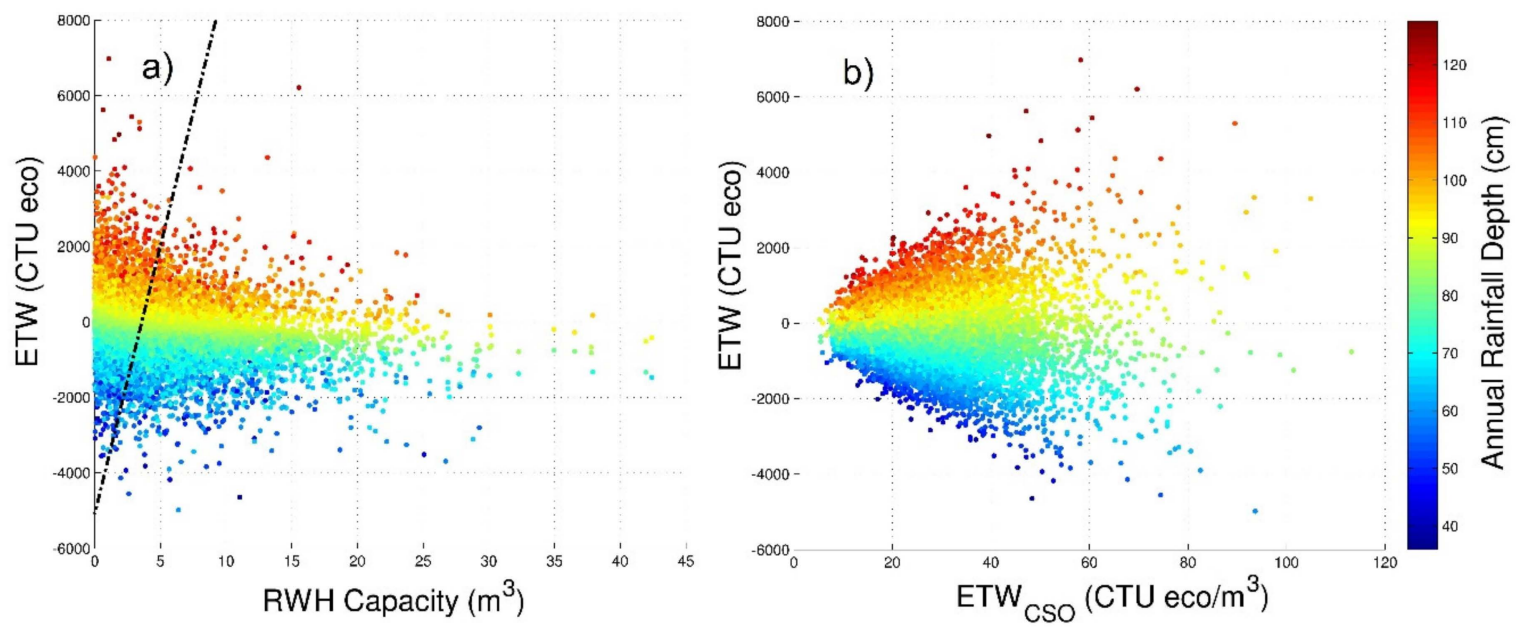

Figure 6. Scatter plots of the MC simulation results for ETW impact corresponding to (a) RWH capacity; and (b) ETW $_{\mathrm{CSD}}$. The dash-dot line shows the partitions boundary obtained from analysis of GWP in Figure 5.

Figure 7 is presented to illustrate the value of components and impacts in two hypothetical scenarios with different RWH capacities and functionalities to provide a clear insight on RWH impacts in the watershed. Values in this figure are differences in the existing condition. Hence, as represented, the volume of CSO is reduced by implementing the RWH system since RWH helps the system to capture CSO in the peak of extreme events. As a result of capturing CSO, the value of ETW is reduced significantly. The avoided CSOs would convey to the WWTP instead of discharging to water bodies. Therefore, it increases ETW and GWP impact. However, for ETW, this increase is much lower than the reduction that caused benefits by avoiding CSOs discharges to water bodies. Thus, the ETW net value stays negative (meaning reducing overall impacts).

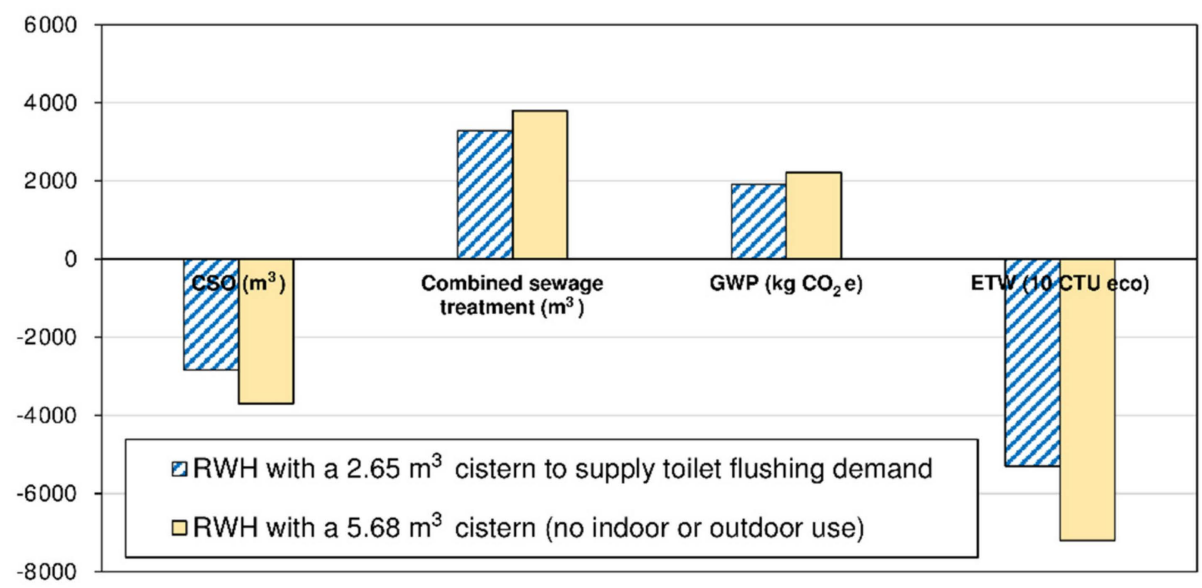

Figure 7. Impact of two RWH scenarios with different capacities (presented values are differences to the existing conditions. i.e., no RWH). Results are for one RWH unit (to achieve this, the first results for having RWH systems on entire building units were obtained. Then, we divided the results by the number of buildings). As presented in this figure, RWH units could avoid CSOs by adding to the drainage system capacity. However, this avoided volume would need to be treated in the treatment facility, which could contribute to the GWP and ETW impacts.

Figure 8 shows the probability density of the MC simulation for the final uWISE outputs. According to this figure, the highest probability of GWP and ETW is approximately associated with 0-5 million $\mathrm{kg} \mathrm{CO}_{2} \mathrm{e}$ and $-500-0$ million CTU eco, respectively. Since these results are based on a change from existing conditions, they indicate that RWH implementation is likely to lead to an increase 
in GWP and a decrease in ETW. In addition, a higher variance was observed in GWP than ETW, which can be explained through the dependency of GWP to rainfall use and dependency of ETW to CSO. The difference in variance of rainfall use and CSO were discussed in Section 3.1.

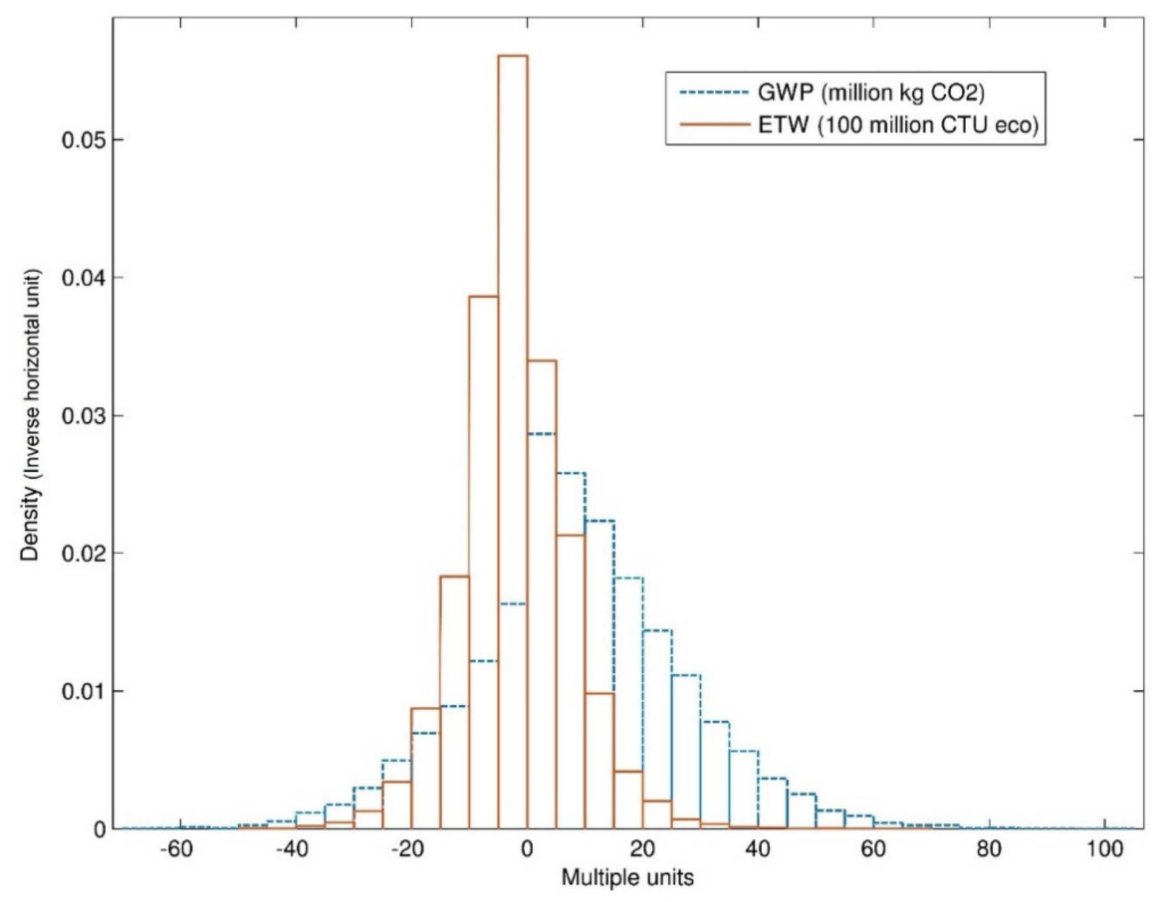

Figure 8. Probability density of the 10,000 MC simulation results for GWP and ETW.

Lastly, the First Order Sensitivity Analysis method identified the relative roles of uncertainty sources to fulfill the goal of uncertainty analysis for the present study. Table 3 summarizes estimates of the portion of uncertainty brought by each parameter, which specifically results in estimating the sensitivity coefficient of each variable using this method. This table indicates that $\mathrm{R}$ is the most significant source of uncertainty with more than $86 \%$ of contribution in propagating the uncertainty. $\mathrm{C}$ was ranked second in this table with around an order of magnitude lower effect. The effects of uncertainties in $\mathrm{GWP}_{\mathrm{CSD}}$ and $\mathrm{ETW}_{\mathrm{CSO}}$ were the lowest. Furthermore, these results (Table 3) indicate that uncertainty in R provides a higher contribution in uncertainty in ETW (94.4\%) than GWP (86.1\%), which stems from the great dependency of ETW to CSO and CSO to rainfall (Figure 3b). These led to a higher effect of $C$ and the LCIA model parameter on GWP compared to ETW.

Table 3. Estimating the sensitivity coefficient of variables using the First Order Sensitivity Analysis method.

\begin{tabular}{ccccccc}
\hline Function $(\boldsymbol{F})$ & Variable $(\boldsymbol{X})$ & Unit & $\frac{\partial \boldsymbol{F}}{\partial \boldsymbol{X}}$ & $\operatorname{Var}(\boldsymbol{X})$ & $\left(\frac{\partial \boldsymbol{F}}{\partial \boldsymbol{X}}\right)^{2} \times \operatorname{Var}(\boldsymbol{X})$ & $\begin{array}{c}\text { Portion of } \\
\text { Uncertainty } \\
\text { Propagated by } \boldsymbol{X}(\mathbf{\%})\end{array}$ \\
\hline \multirow{2}{*}{$\mathrm{GWP}$} & $\mathrm{R}$ & $\mathrm{cm}$ & 0.9 & 165.9 & 152.0 & $86.1 \%$ \\
& $\mathrm{C}$ & $\mathrm{m}^{3}$ & 0.7 & 24.3 & 12.5 & $7.1 \%$ \\
\hline \multirow{2}{*}{$\mathrm{ETW}$} & $\mathrm{GWP}$ & $\mathrm{k} \mathrm{CO}_{2} \mathrm{e} / \mathrm{m}^{3}$ & 8.5 & 0.2 & 12.1 & $6.8 \%$ \\
& $\mathrm{R}$ & $\mathrm{cm}$ & 66.6 & 165.9 & $736,617.1$ & $94.4 \%$ \\
& $\mathrm{C}$ & $\mathrm{m}^{3}$ & -38.7 & 24.3 & $36,366.4$ & $4.7 \%$ \\
$\mathrm{ETW}$ & $\mathrm{CTU} \mathrm{eco} / \mathrm{m}^{3}$ & -5.6 & 242.8 & 7524.3 & $0.9 \%$ \\
\hline
\end{tabular}

\subsection{Model Validation and Discussion}

The present research used average values for water quality of combined sewage, CSOs, and stormwater per their volume. For a higher accuracy, the hydrologic model could be extended to 
include a water quality module in order to directly simulate the pollutant concentration for combined sewage, CSOs, and stormwater over the time. In addition, Toledo's combined sewer network was selected for implantation of this research due to the fact that this city has the lowest level of low impact development plant implementation in its long-term control plan among all the US cities surrounding the Great Lakes [51], while this network may not be a representative site necessarily. Although rainfall varied to account for different climatic conditions, findings of this research still need further corroboration with additional studies on different urban water infrastructure.

To overcome the above deficiencies, the present study considered the highest recommended uncertainty in the LCIA parameters and still found the effect of this uncertainty insignificant when compared to the hydrologic components. This finding emphasizes that, in order to advance the LCA-based design of the urban water infrastructure, increasing the accuracy of long-term performance simulations may be of high importance. This is the key area that we consider our conclusions have impacts on future research and publications.

The case study application suggested that the optimal RWH system capacity could be defined as a linear function of annual rainfall depth. This optimal design would lead to minimized life cycle impacts in terms of global warming potential (GWP) and aquatic Eco-Toxicity (ETW). Capacities smaller than the optimal would make the RWH system lose potable water treatment savings and CSO control benefits, while capacitates larger than the optimal would cause an additional wastewater treatment burden and construction phase impacts. Since the future annual rainfall depth is unknown, for a robust life cycle assessment of water infrastructure plans, robust analysis of the future rainfall considering possible changes and anomalies is needed (e.g., Nasseri et al. [95], Tavakol-Davani et al. [96], Tavakol-Davani et al. [97], and Sinha et al. [98]). The analysis horizon should be consistent with the considered life cycle of the infrastructure (i.e., 75 years for the present study). This is another area that we consider our conclusions may have an impact especially in future studies.

\section{Conclusions}

This study identified the major sources of uncertainty in an integrated framework for an environmentally-sustainable design of urban drainage infrastructure based on hydrologic analysis and the life cycle assessment (LCA). The study compared the uncertainty effects of inaccuracy in LCIA parameters with variability in hydrologic data as input parameters. The uncertainty analysis platform was applied to a watershed-scale LCA of RWH to supply indoor demands and control CSOs. Rainfall, as a hydrologic input parameter, appeared to be the most significant source of uncertainty. Therefore, for a reliable LCA-based urban water infrastructure design, it is necessary to adopt robust hydrologic analysis to inform the operation phase of the LCA. This analysis allows understanding the possible responses of watersheds to variability in rainfall during the life cycle of a water infrastructure. Without hydrologic analysis, the LCA results may not represent the actual impacts of the water infrastructure governed by variability in rainfall. Moreover, analyzing the operation impacts for a short period and projecting it to the entire life cycle may be inappropriate.

This study considered the highest recommended uncertainty in the LCIA parameters and still found the effect of this uncertainty insignificant. To advance the LCA-based design of the urban water infrastructure, increasing the accuracy in compiling LCI may be of a higher importance than defining LCIA parameters. This statement is in need of further corroboration with additional studies in a different urban water infrastructure. The case study application suggested that the optimal RWH system capacity could be defined as a linear function of annual rainfall depth. This optimal design would lead to minimized life cycle impacts in terms of global warming potential (GWP) and aquatic Eco-Toxicity (ETW). Capacities smaller than the optimal would make the RWH system lose potable water treatment savings and CSO control benefits, while capacitates larger than the optimal would cause an additional wastewater treatment burden and construction phase impacts. However, the annual rainfall depth varies each year and may not provide a practical design guideline. Thus, to achieve the minimized impacts, this study suggests RWH capacities to be designed for short periods 
(e.g., 10 years) through robust analysis of the future rainfall considering possible changes and anomalies (e.g., Tavakol-Davani et al. [97]). This statement is in need of further corroboration with additional tests of the presented method for different drainage system capacities and climates.

The present study had limitations that could be addressed by future studies, including:

- As explained in Section 2.1, assessing the LCIA characterization factor uncertainty was beyond the scope of this study. Particularly for ETW results, this could introduce a systematic uncertainty as discussed by Rosenbaum et al. [59] and Wender et al. [60]. However, this limitation may not impact the overall conclusion of the present study drawn from simultaneous GWP and ETW results. Since this limitation could introduce uncertainty regarding the relative significance of different contributors to the aquatic eco-toxicity scores, we suggest a follow up study to focus on aquatic eco-toxicity impacts of RWH incorporating the characterization factors.

- Other sources of uncertainty, i.e., model structural and decision uncertainties, may be studied to provide insight into the overall status of uncertainty of the integrated framework. Such an analysis may identify the areas where the results' reliability can be improved, and, thus, advance the integration of hydrologic and LCA models for urban water infrastructure assessment.

- Other urban drainage infrastructures, e.g., separate sewer systems, detention basins, and pervious pavements may be studied in the future to understand their optimal LCA-based design with a consideration of the existing uncertainties.

- A broader hydrologic representation of the urban drainage system can be considered a follow up study, including water quality simulation modules.

Supplementary Materials: The following are available online at http://www.mdpi.com/2073-4441/11/12/2592/s1, Figure S1: Cumulative probably density functions for parameters selected to perform the uncertainty analysis, Figure S2: Results of topology-inspired regression model, Figure S3: Tributary subwatersheds, major pipes and the interceptor at the case study.

Author Contributions: H.T.-D. contributed in writing the original draft, software techniques, investigation, and visualization. R.R. contributed in writing the revised manuscript, editing, data curation, and validation. S.J.B. contributed in supervision and funding acquisition. C.A.P. contributed in development of the methodology. B.J.M. contributed in the formal analysis. D.A. contributed in providing the resources, conceptualization, writing and editing.

Funding: This paper summarizes the authors' efforts as a part of the urban Water Infrastructures Sustainability Evaluation (uWISE) project funded by the U.S. National Science Foundation (NSF) through grants CBET-1235855 and 1236660. Global Change and Sustainability Center of University of Utah and CI-Water project also supported this research.

Acknowledgments: The corresponding author appreciates the help of Dan Maljovec and Valerio Pascucci from the SCI (Scientific Computing and Imaging) Institute of the University of Utah with the visualization needs for this research.

Conflicts of Interest: The authors declare no conflict of interest.

\section{References}

1. U.S. EPA. Greening CSO Plans: Planning and Modeling Green Infrastructure for Combined Sewer Overflow (CSO) Control; EPA-832-R-14-001; EPA: Washington, DC, USA, 2014.

2. Guo, Y. Hydrologic design of urban flood control detention ponds. J. Hydrol. Eng. 2001, 6, 472-479. [CrossRef]

3. Haan, C.; Barfield, B.; Hayes, J. Design Hydrology and Sedimentology for Small Catchments; Academic Press: San Diego, CA, USA, 1994.

4. Hsu, M.; Chen, S.; Chang, T. Inundation simulation for urban drainage basin with storm sewer system. J. Hydrol. 2000, 234, 21-37. [CrossRef]

5. Flynn, K.; Traver, R. Green infrastructure life cycle assessment: A bio-infiltration case study. Ecol. Eng. 2013, 55, 9-22. [CrossRef]

6. Ghimire, S.R.; Johnston, J.; Ingwersen, W.; Hawkins, T. Life Cycle Assessment of domestic and agricultural rainwater harvesting systems. Environ. Sci. Technol. 2014, 48, 4069-4077. [CrossRef] 
7. Stokes, J.; Horvath, A.R. Life-cycle assessment of urban water provision: Tool and case study in California. J. Infrastruct. Syst. 2011, 17, 15-24. [CrossRef]

8. Vineyard, D.; Ingwersen, W.; Hawkins, R.; Xue, X.; Demeke, B.; Shuster, W. Comparing green and grey infrastructure using life cycle cost and environmental impact: A rain garden case study in Cincinnati, $\mathrm{OH}$. J. Am. Water Resour. Assoc. 2015. [CrossRef]

9. Gao, H.; Zhou, C.; Li, F.; Han, B.; Li, X. Economic and environmental analysis of five Chinese rural toilet technologies based on the economic input-output life cycle assessment. J. Clean. Prod. 2017, 163, 379-391. [CrossRef]

10. ISO (International Organization for Standardization). Environmental Management-Life Cycle Assessment-Requirements and Guidelines; ISO 14044; ISO: Geneva, Switzerland, 2006.

11. Zhou, Q. A review of sustainable urban drainage systems considering the climate change and urbanization impacts. Water 2014, 6, 976-992. [CrossRef]

12. De Sousa, M.; Montalto, F.; Spatari, S. Using life cycle assessment to evaluate green and grey combined sewer overflow control strategies. J. Ind. Ecol. 2012, 16, 901-913. [CrossRef]

13. Wang, R.; Eckelman, M.; Zimmerman, J. Consequential environmental and economic life cycle assessment of green and gray Stormwater infrastructures for combined sewer systems. Environ. Sci. Technol. 2013, 47, 11189-11198. [CrossRef]

14. Petit-Boix, A.; Devkota, J.; Phillips, R.; Vargas-Parra, M.V.; Josa, A.; Gabarrell, X.; Rieradevall, J.; Apul, D. Life cycle and hydrologic modeling of rainwater harvesting in urban neighborhoods: Implications of urban form and water demand patterns in the US and Spain. Sci. Total Environ. 2018, 621, 434-443. [CrossRef]

15. Lucas, W. Design of integrated bioinfiltration-detention urban retrofits with design storm and continuous simulation methods. J. Hydrolog. Eng. 2010, 15, 486-498. [CrossRef]

16. Ghimire, S.R.; Johnston, J. Impacts of domestic and agricultural rainwater harvesting systems on watershed hydrology: A case study in the Albemarle-Pamlico river basins (USA). Ecohydrol. Hydrobiol. 2015, 13, 159-171. [CrossRef]

17. Shadeed, S.; Lange, J. Rainwater harvesting to alleviate water scarcity in dry conditions: A case study in Faria Catchment, Palestine. Water Sci. Eng. 2010, 3, 132-143. [CrossRef]

18. Devkota, J.; Burian, S.; Tavakol-Davani, H.; Apul, D. Introducing demand to supply ratio as a new metric for understanding life cycle greenhouse gas (GHG) emissions from rainwater harvesting systems. J. Clean. Prod. 2017, 163, 274-284. [CrossRef]

19. Malinowski, P.A.; Stillwell, A.S.; Wu, J.S.; Schwarz, P.M. Energy-water nexus: Potential energy savings and implications for sustainable integrated water management in urban areas from rainwater harvesting and gray-water reuse. J. Water Resour. Plan. Manag. 2015, 141, A4015003. [CrossRef]

20. Morales-Pinzon, T.; Rieradevall, J.; Gasol, C.; Gabarrell, X. Modelling for economic cost and environmental analysis of rainwater harvesting systems. J. Clean. Prod. 2015, 87, 613-626. [CrossRef]

21. Vargas-Parra, M.; Villalba, G.; Gabarrell, X. Applying exergy analysis to rainwater harvesting systems to assess resource efficiency. Resour. Conserv. Recycl. 2013, 72, 50-59. [CrossRef]

22. Vieira, A.; Beal, C.; Ghisi, E.; Stewart, R. Energy intensity of rainwater harvesting systems: A review. Renew. Sustain. Energy. Rev. 2014, 34, 225-242. [CrossRef]

23. Philadelphia's Green City Clean Waters Program. Concurrent II: Stormwater and Water Treatment. Engineering Sustainability 2015: Innovation and the Triple Bottom Line. 2015. Available online: http://www.usgbc.org/education/sessions/engineering-sustainability-2015-innovation-and-triplebottom-line/concurrent-ii-s (accessed on 18 December 2015).

24. Yoshida, H.; Clavreul, J.; Scheutz, C.; Christensen, T. Influence of Data Collection Schemes on the Life Cycle Assessment of a Municipal Wastewater Treatment Plant. Water Res. 2014, 56, 292-303. [CrossRef]

25. Weidema, B.; Bauer, C.; Hischier, R.; Mutel, C.; Nemecek, T.; Reinhard, J.; Vadenbo, C.; Wernet, G. Overview and Methodology_Data Quality Guideline for the Ecoinvent Database; Version 3; Swiss Centre for Life Cycle Inventories: St. Gallen, Switzerland, 2013.

26. Harder, R.; Holmquist, H.; Molander, S.; Svanstrom, M.; Peters, G. Review of Environmental Assessment Case Studies Blending Elements of Risk Assessment and Life Cycle Assessment. Environ. Sci. Technol. 2015, 49, 13083-13093. [CrossRef] [PubMed]

27. Baker, J.; Lepech, M. Treatment of Uncertainties in Life Cycle Assessment. In Proceedings of the 10th International Congress on Structural Safety and Reliability, Osaka, Japan, 13-17 September 2009. 
28. U.S. EPA. Environmental and Cost Life Cycle Assessment of Disinfection Options for Municipal Wastewater Treatment; EPA 600/R-14/377; EPA: Washington, DC, USA, 2014.

29. Cowell, S.; Fairman, R.; Lofstedt, R. Use of Risk Assessment and Life Cycle Assessment in Decision Making: A Common Policy Research Agenda. Risk Anal. 2002, 22, 879-894. [CrossRef] [PubMed]

30. Huijbregts, M. Application of uncertainty and variability in LCA-Part I: A general framework for the analysis of uncertainty and variability in life cycle assessment. Int. J. Life Cycle Assess. 1998, 3, 273-280. [CrossRef]

31. Huijbregts, M. Application of uncertainty and variability in LCA-Part II: Dealing with parameter uncertainty and uncertainty due to choices in life cycle assessment. Int. J. Life Cycle Assess. 1998, 3, 343-351. [CrossRef]

32. Heijungs, R.; Huijbregts, A. A review of approaches to treat uncertainties in LCA. In Proceedings of the 2nd Biennial Meeting of the International Environmental Modelling and Software Society (iEMSs), Manno, Switzerland, 1 June 2004; pp. 332-339.

33. Dones, R.; Heck, T.; Emmenegger, M.; Jungbluth, N. Life cycle inventories for the nuclear and natural gas energy systems, and examples of uncertainty analysis. Int. J. Life Cycle Assess. 2005, 10, 10-23. [CrossRef]

34. Grant, T. Inclusion of uncertainty in LCA. In Proceedings of the Fourth Australian Conference on Life Cycle Assessment-Sustainability Measures for Decision Support, Sydney, NSW, Australia, 23-25 February 2005.

35. Sonneman, G.; Schuhmacher, M.; Castells, F. Uncertainty assessment by a Monte Carlo simulation in a life cycle inventory of electricity produced by a waste incinerator. J. Clean. Prod. 2003, 11, 279-292. [CrossRef]

36. Andrae, A.; Moller, P.; Anderson, J.; Liu, J. Uncertainty estimation by Monte Carlo simulation Applied to Life Cycle Inventory of cordless phones and microscale metallization processes. IEEE Trans. Electron. Packag. Manuf. 2004, 27, 206-217. [CrossRef]

37. Basset-Mens, C.; Werf, H.M.G.; Durand, P.; Leterme, P. Implications of uncertainty and variability in the Life Cycle Assessment of pig farming systems. In Proceedings of the Transactions of the 2nd Biennial Meeting of the International Environmental Modelling and Software Society (iEMSs), Manno, Switzerland, 1 July 2004.

38. Ferret, R.; Mendoza, G.; Castilla, M. The influence of agricultural data uncertainty in the life cycle assessment of biodegradable hydraulic lubricants. In Proceedings of the 2nd Biennial Meeting of the International Environmental Modelling and Software Society (iEMSs), Eibar, Spain, 14-17 June 2004.

39. Contadini, J. Life Cycle Assessment of Fuel Cell Vehicles-Dealing with Uncertainties; Application of Uncertainties in LCA; UC Davis: Davis, CA, USA, 2002.

40. Zhang, Y.; Vidakovic, B. Uncertainty Analysis in Using Markov Chain Model to Predict Roof Life Cycle Performance; Georgia Institute of Technology: Lyon, France, 2005.

41. Hongxiang, C.; Wei, C. Uncertainty analysis by Monte Carlo simulation in a Life Cycle Assessment of water-saving project in green buildings. Inf. Technol. J. 2013, 12, 2593-2598. [CrossRef]

42. Niero, M.; Pizzol, M.; Bruun, H.G.; Thomsen, M. Comparative life cycle assessment of wastewater treatment in Denmark including sensitivity and uncertainty analysis. J. Clean. Prod. 2014, 68, 25-35. [CrossRef]

43. Ciroth, A.; Fleischer, G.; Steinbach, J. Uncertainty calculation in life cycle assessments-A combined model of simulation and approximation. Int. J. Life Cycle Assess. 2004, 9, 216-226. [CrossRef]

44. Guo, M.; Murphy, R.J. LCA data quality: Sensitivity and uncertainty analysis. Sci. Total Environ. 2012, 435, 230-243. [CrossRef] [PubMed]

45. Hung, M.; Ma, H. Quantifying system uncertainty of life cycle assessment based on Monte Carlo simulation. Int. J. Life Cycle Assess. 2009, 14, 19-27. [CrossRef]

46. Burian, S.J.; Jones, D. National assessment of rainwater harvesting as a stormwater best management practice: Challenges, needs, and recommendations. In Proceedings of the 2010 International Low Impact Development Conference, ASCE, Reston, VA, USA, 11-14 April 2010.

47. Jones, M.; Hunt, W. Performance of rainwater harvesting systems in the southeastern United States. Resour. Conserv. Recycl. 2010, 54, 623-629. [CrossRef]

48. Mehrabadi, M.H.; Saghafian, B.; Fashi, F. Assessment of residential rainwater harvesting efficiency for meeting non-potable water demands in three climate conditions. Resour. Conserv. Recycl. 2013, 73, 86-93. [CrossRef]

49. Sample, D.; Liu, J. Optimizing rainwater harvesting systems for the dual purposes of water supply and runoff capture. J. Clean. Prod. 2014, 75, 174-194. [CrossRef]

50. Steffen, J.; Jensen, M.; Pomeroy, C.; Burian, S. Water supply and stormwater management benefits of residential rainwater harvesting in U.S. cities. J. Am. Water Resour. Assoc. 2013, 49, 810-824. [CrossRef] 
51. Tavakol-Davani, H.; Burian, S.J.; Devkota, J.; Apul, D. Performance and Cost Based Comparison of Green and Gray Infrastructure to Control Combined Sewer Overflows. J. Sustain. Water Built Environ. 2015, 2, 04015009. [CrossRef]

52. Thomas, R.; Kirisits, M.; Lye, D.; Kinney, K. Rainwater harvesting in the United States: A survey of common system practices. J. Clean. Prod. 2014, 75, 166-173. [CrossRef]

53. Gerber, S.; Rubel, O.; Bremer, P.; Pascucci, V.; Whitaker, R. Morse-smale regression. J. Comput. Graph. Stat. 2013, 22, 193-214. [CrossRef] [PubMed]

54. Maljovec, D.; Wang, B.; Rosen, P.; Alfonsi, A.; Pastore, G.; Rabiti, C.; Pascucci, V. Rethinking sensitivity analysis of nuclear simulations with topology. In Proceedings of the IEEE Pacific Visualization Symposium, Taipei, Taiwan, 19-22 April 2016.

55. Cellura, M.; Longo, S.; Mistretta, M. Sensitivity analysis to quantify uncertainty in life cycle assessment: The case study of an Italian tile. Renew. Sustain. Energy Rev. 2011, 15, 4697-4705. [CrossRef]

56. Dotto, C.; Mannina, G.; Kleidorfer, M.; Vezzaro, L.; Henrichs, M.; McCarthy, D.; Freni, G.; Rauch, W.; Deletic, A. Comparison of different uncertainty techniques in urban stormwater quantity and quality modeling. Water Res. 2012, 46, 2545-2558. [CrossRef] [PubMed]

57. Leta, O.T.; Nossent, J.; Velez, C.; Shrestha, N.K.; Griensven, A.; Bauwens, W. Assessment of the different sources of uncertainty in a SWAT model of the River Senne (Belgium). Environ. Model. Softw. 2015, 68, 129-146. [CrossRef]

58. Loucks, D.; Van Beek, E. Water Resources Systems Planning and Management. An Introduction to Methods, Models and Applications; UNESCO Publishing: Paris, France, 2005; ISBN 92-3-103998-9.

59. Rosenbaum, R.K.; Bachmann, T.M.; Gold, L.S.; Huijbregts, M.A.; Jolliet, O.; Juraske, R.; Koehler, A.; Larsen, H.F.; MacLeod, M.; Margni, M.; et al. USEtox-The UNEP-SETAC toxicity model: recommended characterisation factors for human toxicity and freshwater ecotoxicity in life cycle impact assessment. Int. J. Life Cycle Assess. 2008, 13, 532. [CrossRef]

60. Wender, B.A.; Prado, V.; Fantke, P.; Ravikumar, D.; Seager, T.P. Sensitivity-based research prioritization through stochastic characterization modeling. Int. J. Life Cycle Assess. 2018, 23, 324-332. [CrossRef]

61. Tavakol-Davani, H.; Burian, S.J.; Butler, D.; Sample, D.; Devkota, J.; Apul, D. Combining Hydrologic Analysis and Life Cycle Assessment Approaches to Evaluate Sustainability of Water Infrastructure. J. Irrig. Drain. Eng. 2018, 144, 05018006. [CrossRef]

62. Rossman, L. Storm Water Management Model User's Manual: Volume I-Hydrology; U.S. Environmental Protection Agency: Cincinnati, OH, USA, 2015.

63. Chang, N.B.; Lu, J.W.; Chui, T.F.M.; Hartshorn, N. Global policy analysis of low impact development for stormwater management in urban regions. Land Use Policy 2018, 70, 368-383. [CrossRef]

64. Barrios, R.; Siebel, M.; Van Der Helm, A.; Bosklopper, K.; Gijzen, H. Environmental and financial life cycle impact assessment of drinking water production at Waternet. J. Clean. Prod. 2008, 16, 471-476. [CrossRef]

65. Bonton, A.; Bouchard, C.; Barbeau, B.; Jedrzejak, S. Comparative life cycle assessment of water treatment plants. Desalination 2012, 284, 42-54. [CrossRef]

66. Ghimire Santosh, R.; John, M.; Johnston, W.W.; Sarah, S. Life cycle assessment of a commercial rainwater harvesting system compared with a municipal water supply system. J. Clean. Prod. 2017, 151, 74-86. [CrossRef]

67. Roushdi, M.; El-Hawary, A.; Mahgoub, M. Environmental Improvement of Alexandria's Wastewater Treatment Plants using Life Cycle Assessment Approach. Glob. NEST J. 2012, 14, 450-459. [CrossRef]

68. PE International. Gabi Database. 2014. Available online: http://www.pe-international.com (accessed on 17 July 2014).

69. Bare, J. TRACI 2.0: the tool for the reduction and assessment of chemical and other environmental impacts 2.0. Clean Technol. Environ. Policy 2011, 13, 687-696. [CrossRef]

70. Florida Rainwater Harvesting Initiative. Rainwater Harvesting with Cisterns. Florida Water Star ${ }^{\mathrm{SM}} .2009$. Available online: http://floridawaterstar.com/pdfs/RWH_Guide_2009-10.pdf (accessed on 18 October 2014).

71. Sanjuan-Delmas, D.; Petit-Boix, A.; Gasol, C.; Villalba, G.; Suarez-Ojeda, M.; Gabarrell, X.; Josa, A.; Rieradevall, J. Environmental assessment of different pipelines for drinking water transport and distribution network in small to medium cities: A case from Betanzos, Spain. J. Clean. Prod. 2014, 66, 588-598. [CrossRef]

72. Hamby, D. A comparison of sensitivity analysis techniques. Health Phys. 1995, 68, 195-204. [CrossRef] [PubMed] 
73. Zahmatkesh, Z.; Karamouz, M.; Nazif, S. Uncertainty based modeling of rainfall-runoff: Combined differential evolution adaptive Metropolis (DREAM) and K-means clustering. Adv. Water Resour. 2015, 83, 405-420. [CrossRef]

74. Chilton, J.; Maidment, G.; Marriott, D.; Francis, A.; Tobias, G. Case study of a rainwater recovery system in a commercial building with a large roof. Urban Water 2000, 1, 345-354. [CrossRef]

75. Lash, D.; Ward, S.; Kershaw, T.; Butler, D.; Eames, M. Robust rainwater harvesting: Probabilistic tank sizing for climate change adaptation. J. Water Clim. Chang. 2014, 5, 526-539. [CrossRef]

76. Matos, C.; Santos, C.; Pereira, S.; Bentes, I.; Imteaz, M. Rainwater storage tank sizing: Case study of a commercial building. Int. J. Sustain. Built Environ. 2013, 2, 109-118. [CrossRef]

77. Ward, S.; Memon, F.A.; Butler, D. Rainwater harvesting: Model-based design evaluation. Water Sci. Technol. 2010, 61, 85-96. [CrossRef]

78. Campisano, A.; Butler, D.; Ward, S.; Burns, M.J.; Friedler, E.; DeBusk, K.; Fisher-Jeffes, L.N.; Ghisi, E.; Rahman, A.; Furumai, H.; et al. Urban rainwater harvesting systems: Research, implementation and future perspectives. Water Res. 2017, 115, 195-209. [CrossRef]

79. Avellaneda, P.M.; Jefferson, A.J.; Grieser, J.M.; Bush, S.A. Simulation of the cumulative hydrological response to green infrastructure. Water Resour. Res. 2017, 53, 3087-3101. [CrossRef]

80. Metropolis, N.; Ulam, S. The Monte Carlo method. J. Am. Stat. Assoc. 1949, 44, 335-341. [CrossRef]

81. Elishakoff, I.; van Manen, S.; Vermeulen, P.G.; Arbocz, J. First-order second moment analysis of the buckling of shells with random imperfections. AIAA J. 1987, 25, 1113-1117. [CrossRef]

82. Metropolis, N.; Rosenbluth, A.; Rosenbluth, M.; Teller, A.; Teller, E. Equation of state calculations by fast computing machines. J. Chem. Phys. 1953, 21, 1087-1092. [CrossRef]

83. Hastings, W. Monte Carlo sampling methods using markov chains and their applications. Biometrika 1970, 57, 97-109. [CrossRef]

84. Vrugt, J.; Ter Braak, C.; Diks, C.; Robinson, B.; Hyman, J.; Higdon, D. Accelerating Markov Chain Monte Carlo simulation by differential evolution with self-adaptive randomized subspace sampling. Int. J. Nonlinear Sci. Numer. Simul. 2009, 10, 273-290. [CrossRef]

85. Cowles, M.K.; Carlin, B.P. Markov Chain Monte Carlo convergence diagnostics: A comparative review. J. Am. Stat. Assoc. 1996, 91, 883-904. [CrossRef]

86. Gelman, A.; Shirley, K. Inference from Simulations and Monitoring Convergence. In Handbook of Markov Chain Monte Carlo; CRC Press: London, UK, 2011; pp. 163-174.

87. HTCondor. 2015. Available online: https://research.cs.wisc.edu/htcondor/ (accessed on 17 July 2014).

88. Tavakol-Davani, H.E.; Tavakol-Davani, H.; Burian, S.J.; McPherson, B.J.; Barber, M.E. Green infrastructure optimization to achieve pre-development conditions of a semiarid urban catchment. J. Environ. Sci. 2019, 5, 1157-1171. [CrossRef]

89. Tavakol-Davani, H.E.; Tavakol-Davani, H.; Burian, S.J. Evolutionary Optimization of Green Infrastructure by High Throughput Computing. In Proceedings of the 2019 World Environmental and Water Resources Congress, ASCE, Pittsburgh, PA, USA, 19-23 May 2019. [CrossRef]

90. U.S. Climate Data. Climate Toledo-Ohio. Available online: http://www.usclimatedata.com/climate/toledo/ ohio/united-states/usoh0953 (accessed on 17 July 2014).

91. City of Toledo. Flow Characterization Study Report; Toledo Waterways Initiative: Toledo, OH, USA, 2005.

92. Tavakol-Davani, H. Watershed-Scale Life Cycle Assessment of Rainwater Harvesting Systems to Control Combined Sewer Overflows. Ph.D. Thesis, University of Utah, Salt Lake City, UT, USA, 2016.

93. AREIS. Auditor's Real Estate Information System; CD-ROM; AREIS: Toledo, OH, USA, 2014.

94. City of Toledo. Toledo Waterways Initiative; Toledo Waterways Initiative: Toledo, OH, USA, 2014; Available online: http://www.toledowaterwaysinitiative.com/ (accessed on 17 July 2014).

95. Nasseri, M.; Tavakol-Davani, H.; Zahraie, B. Performance assessment of different data mining methods in statistical downscaling of daily precipitation. J. Hydrol. 2013, 492, 1-14. [CrossRef]

96. Tavakol-Davani, H.; Nasseri, M.; Zahraie, B. Improved statistical downscaling of daily precipitation using SDSM platform and data-mining methods. Int. J. Climatol. 2013, 33, 2561-2578. [CrossRef] 
97. Tavakol-Davani, H.E.; Goharian, E.; Hansen, C.H.; Tavakol-Davani, H.; Apul, D.; Burian, S.J. How does climate change affect combined sewer overflow in a system benefiting from rainwater harvesting systems? Sustain. Cities Soc. 2016, 27, 430-438. [CrossRef]

98. Sinha, P.; Mann, M.E.; Fuentes, J.D.; Mejia, A.; Ning, L.; Sun, W.; He, T.; Obeysekera, J. Downscaled rainfall projections in south Florida using self-organizing maps. Sci. Total Environ. 2018, 635, 1110-1123. [CrossRef]

(C) 2019 by the authors. Licensee MDPI, Basel, Switzerland. This article is an open access article distributed under the terms and conditions of the Creative Commons Attribution (CC BY) license (http://creativecommons.org/licenses/by/4.0/). 